\title{
Third Molar Impaction Characteristics among Three Different Patterns of Growth Rotations
}

\author{
Sanjeev Datana ${ }^{1}$, Saugat Ray ${ }^{2}$, Amit Jain ${ }^{3}$, Mohit Sharma ${ }^{4}$, Prasanna Kumar MP ${ }^{5}$ \\ ${ }^{1}$ Associate Professor, Department of Dental Surgery and Oral Health Sciences AFMC, Pune, ${ }^{2}$ Classified Specialist, NIDS, \\ RC Church, Colaba, Mumbai, ${ }^{3}$ Reader and Instructor, Department of Dental Surgery and Oral Health Sciences AFMC, \\ Pune, ${ }^{4}$ Reader and Instructor, Department of Dental Surgery and Oral Health Sciences AFMC, Pune, ${ }^{5}$ Associate Professor, \\ Department of Orthodontics, AFMC, Pune, India
}

Corresponding author: Sanjeev Datana, Associate Professor, Department of Dental Surgery and Oral Health Sciences AFMC, Pune, Maharashtra, India

DOI: http://dx.doi.org/10.21276/ijcmsr.2018.3.4.31

How to cite this article: Sanjeev Datana, Saugat Ray, Amit Jain, Mohit Sharma, Prasanna Kumar MP. Third molar impaction characteristics among three different patterns of growth rotations. International Journal of Contemporary Medicine Surgery and Radiology. 2018;3(4):D137-D141.

\section{A B S T R A C T}

Introduction: The effects of facial skeleton dimensions and growth pattern on impaction of mandibular third molar had always been a debatable topic. The present study intends to evaluate the vertical growth pattern on patients with impacted mandibular third molar and their correlation. The aim and objectives of this study was to find out the correlation between various skeletal vertical parameters of face with impaction of mandibular third molar.

Material and methods: The radiographs of 66 patients having bilateral impacted mandibular third molars were collected after applying different exclusion and inclusion criteria. Lateral cephalograms were traced and cephalometric parameters were noted. Third molar angulations in relation to mandibular plane were noted.

Result: $59.09 \%$ patients were vertical growers, with mean FMA of $29.80 \pm 2.36$ and mean lower anterior facial height (LAFH) being $58.75 \pm 1.70 \mathrm{~mm}$. A very few $7.57 \%$ were horizontal growers with mean FMA of $19.37 \pm 1.10$ and mean LAFH being $73.01 \pm 3.43 \mathrm{~mm}$. Mean third molar angulations in vertical, horizontal and average growers were $77.88^{\circ} \pm 10.33,72.4^{\circ} \pm$ 19.78 and $84^{\circ} \pm 2.42$ respectively which was found to be statistically insignificant.

Conclusion: It is concluded that the non eruption or impaction of mandibular third molar is independent of vertical growth pattern of an individual.

Key words: Third molar angulations, Impaction, Growth Rotations

\section{INTRODUCTION}

The prevalence of impaction of mandibular third molars are the highest among other any other impacted teeth in the oral cavity. ${ }^{1,2}$ They are commonly found associated with various localized complications viz carious second or third molars pericoronitis due to inaccessibility for maintaining adequate oral hygiene methods and even to the extent of severe space infections of head and neck region. As discussed in the previous part of the study one of the potential etiology of mandibular third molar getting impacted is inadequate space in the retromolar region between second molars and anterior border of ascending ramus of the mandible., 3 Broadbent and Bjork also suggested that the deficient growth potential along with the downward rotation of mandible, to be one of the potential cause of mandibular third molar impaction., ${ }^{3,5}$ The studies on Australian aboriginal skulls by Begg suggested that, the present day food habits in modern human being causes lack of interproximal attrition which may attribute to the inadequate forward movement of mandibular teeth and hence results in the impaction of mandibular third molars. ${ }^{6}$ Hence he suggested the extraction of four premolar teeth for gaining space gain in alveolar arch for orthodontic correction of tooth size arch length discrepancies. Few authors had even suggested for extractions of second molars to facilitate the eruption of third molars in place and hence preventing the chances of mandibular and maxillary third molars getting impacted. ${ }^{7,8}$

Few authors advocated that individuals with increased mandibular plane angles or vertical growth pattern shows two times higher incidence of third-molar impaction compared to subjects with brachycephalic pattern. ${ }^{9,10}$ Richardson ${ }^{11}$, in a longitudinal study also found the significant number of third molar impactions in cases of skeletal Class II malocclusion with smaller mandibular dimensions which is in consensus with the previous part of the present study.

Various authors suggested additional factors which affects the eruption pattern of mandibular third molar, like ethnicity and race of an individual and change of geographical locations. ${ }^{12,13}$

The aim of the present study is to find out correlation between the impaction of mandibular third molars with the vertical dimensions of maxillo mandibular region. The 


\begin{tabular}{|c|c|c|c|c|c|c|c|c|c|}
\hline & & \multirow[t]{2}{*}{$\mathbf{N}$} & \multirow[t]{2}{*}{ Mean } & \multirow[t]{2}{*}{$\begin{array}{l}\text { Std. De- } \\
\text { viation }\end{array}$} & \multirow[t]{2}{*}{$\begin{array}{l}\text { Std. } \\
\text { Error }\end{array}$} & \multicolumn{2}{|c|}{$\begin{array}{l}\text { 95\% Confidence } \\
\text { Interval for Mean }\end{array}$} & \multirow[t]{2}{*}{$\begin{array}{l}\text { Mini- } \\
\text { mum }\end{array}$} & \multirow[t]{2}{*}{$\begin{array}{l}\text { Maxi- } \\
\text { mum }\end{array}$} \\
\hline & & & & & & $\begin{array}{l}\text { Lower } \\
\text { Bound }\end{array}$ & $\begin{array}{l}\text { Upper } \\
\text { Bound }\end{array}$ & & \\
\hline \multirow[t]{4}{*}{ Sum of post angles } & Horizontal growth pattern & 5 & 388.5000 & 1.00000 & .44721 & 387.2583 & 389.7417 & 387.00 & 389.50 \\
\hline & Average growth pattern & 22 & 395.2273 & 1.86271 & .39713 & 394.4014 & 396.0532 & 390.50 & 398.00 \\
\hline & Vertical growth pattern & 39 & 400.0256 & 1.33746 & .21416 & 399.5921 & 400.4592 & 398.50 & 403.50 \\
\hline & Total & 66 & 397.5530 & 3.74590 & .46109 & 396.6322 & 398.4739 & 387.00 & 403.50 \\
\hline \multirow[t]{4}{*}{ FMA } & Horizontal growth pattern & 5 & 19.2000 & 1.03682 & .46368 & 17.9126 & 20.4874 & 18.00 & 20.50 \\
\hline & Average growth pattern & 22 & 25.2273 & 1.52540 & .32522 & 24.5509 & 25.9036 & 23.00 & 28.00 \\
\hline & Vertical growth pattern & 39 & 29.4872 & 2.32120 & .37169 & 28.7347 & 30.2396 & 27.00 & 39.00 \\
\hline & Total & 66 & 27.2879 & 3.65225 & .44956 & 26.3900 & 28.1857 & 18.00 & 39.00 \\
\hline \multirow[t]{4}{*}{ Sn-go gn } & Horizontal growth pattern & 5 & 26.8000 & 1.64317 & .73485 & 24.7597 & 28.8403 & 25.00 & 29.00 \\
\hline & Average growth pattern & 22 & 32.9773 & 1.84182 & .39268 & 32.1607 & 33.7939 & 30.00 & 36.00 \\
\hline & Vertical growth pattern & 39 & 37.7051 & 2.23524 & .35792 & 36.9805 & 38.4297 & 27.50 & 43.00 \\
\hline & Total & 66 & 35.3030 & 3.87783 & .47733 & 34.3497 & 36.2563 & 25.00 & 43.00 \\
\hline \multirow[t]{4}{*}{ LAFH } & Horizontal growth pattern & 5 & 59.4000 & 2.07364 & .92736 & 56.8252 & 61.9748 & 57.00 & 62.00 \\
\hline & Average growth pattern & 22 & 68.8636 & 3.26665 & .69645 & 67.4153 & 70.3120 & 63.00 & 74.00 \\
\hline & Vertical growth pattern & 39 & \begin{tabular}{|l|}
72.7821 \\
\end{tabular} & 3.50525 & .56129 & 71.6458 & 73.9183 & 68.00 & 80.00 \\
\hline & Total & 66 & 70.4621 & 4.93988 & .60806 & 69.2477 & 71.6765 & 57.00 & 80.00 \\
\hline \multirow[t]{4}{*}{3 Molar angulations } & Horizontal growth pattern & 5 & \begin{tabular}{|l|}
72.4000 \\
\end{tabular} & 19.78130 & 8.84647 & 47.8383 & 96.9617 & 38.00 & 87.00 \\
\hline & Average growth pattern & 22 & \begin{tabular}{|l|}
79.8182 \\
\end{tabular} & 8.99543 & 1.91783 & 75.8298 & 83.8065 & 58.00 & 95.00 \\
\hline & Vertical growth pattern & 39 & 77.8846 & 10.33992 & 1.65571 & 74.5328 & 81.2364 & 55.00 & 96.00 \\
\hline & Total & 66 & 78.1136 & 10.78203 & 1.32718 & 75.4631 & 80.7642 & 38.00 & 96.00 \\
\hline \multirow{4}{*}{$\begin{array}{l}\text { Retro molar Space } \\
\text { discrepancy }\end{array}$} & Horizontal growth pattern & 5 & -1.1000 & 2.53476 & 1.13358 & -4.2473 & 2.0473 & -4.00 & 2.50 \\
\hline & Average growth pattern & 22 & -2.1591 & 4.84617 & 1.03321 & -4.3078 & -.0104 & -22.00 & 2.00 \\
\hline & Vertical growth pattern & 39 & -2.3333 & 1.88251 & .30144 & -2.9436 & -1.7231 & -6.00 & 3.00 \\
\hline & Total & 66 & -2.1818 & 3.18728 & .39233 & -2.9653 & -1.3983 & -22.00 & 3.00 \\
\hline
\end{tabular}

\begin{tabular}{|c|c|c|c|c|c|c|}
\hline & & Sum of Squares & df & Mean Square & $\mathbf{F}$ & Sig. \\
\hline \multirow[t]{3}{*}{ Sum of post angles } & Between Groups & 767.226 & 2 & 383.613 & 166.860 & .000 \\
\hline & Within Groups & 144.838 & 63 & 2.299 & & \\
\hline & Total & 912.064 & 65 & & & \\
\hline \multirow[t]{3}{*}{ FMA } & Between Groups & 609.123 & 2 & 304.562 & 74.396 & .000 \\
\hline & Within Groups & 257.907 & 63 & 4.094 & & \\
\hline & Total & 867.030 & 65 & & & \\
\hline \multirow[t]{3}{*}{ Sn-go gn } & Between Groups & 705.542 & 2 & 352.771 & 81.739 & .000 \\
\hline & Within Groups & 271.898 & 63 & 4.316 & & \\
\hline & Total & 977.439 & 65 & & & \\
\hline \multirow[t]{3}{*}{ LAFH } & Between Groups & 877.967 & 2 & 438.983 & 39.052 & .000 \\
\hline & Within Groups & 708.188 & 63 & 11.241 & & \\
\hline & Total & 1586.155 & 65 & & & \\
\hline \multirow[t]{3}{*}{3 Molar angulations } & Between Groups & 229.194 & 2 & 114.597 & .985 & .379 \\
\hline & Within Groups & 7327.203 & 63 & 116.305 & & \\
\hline & Total & 7556.398 & 65 & & & \\
\hline \multirow[t]{3}{*}{ Retro molar Space discrepancy } & Between Groups & 6.758 & 2 & 3.379 & .326 & .723 \\
\hline & Within Groups & 653.560 & 63 & 10.374 & & \\
\hline & Total & 660.318 & 65 & & & \\
\hline \multicolumn{7}{|c|}{ Table-2: One way ANOVA } \\
\hline
\end{tabular}

study primarily focuses on the effects of mandibular growth rotations on mandibular third molar angulations which may result in the non eruption or impaction of mandibular third molars.

The objectives of this study were to find out the correlation of various vertical parameters of maxilla mandibular region with impaction of mandibular third molar.

\section{MATERIAL AND METHODS}

The sample for this multicentric cross sectional study was 


\begin{tabular}{|c|c|c|c|c|c|c|c|}
\hline \multicolumn{2}{|l|}{ Tukey HSD } & \multirow{3}{*}{ (J) group } & \multirow{3}{*}{$\begin{array}{c}\text { Mean } \\
\text { Difference } \\
(\mathrm{I}-\mathrm{J})\end{array}$} & \multirow{3}{*}{$\begin{array}{l}\text { Std. } \\
\text { Error }\end{array}$} & \multirow{3}{*}{ Sig. } & & \\
\hline \multirow[t]{2}{*}{ Dependent Variable } & \multirow[t]{2}{*}{ (I) group } & & & & & \multicolumn{2}{|c|}{$\begin{array}{l}\text { 95\% Confidence } \\
\text { Interval }\end{array}$} \\
\hline & & & & & & $\begin{array}{l}\text { Lower } \\
\text { Bound }\end{array}$ & $\begin{array}{l}\text { Upper } \\
\text { Bound }\end{array}$ \\
\hline \multirow[t]{6}{*}{ Sum of posterior angles } & \multirow[t]{2}{*}{ Horizontal growth pattern } & Average growth pattern & $-6.72727^{*}$ & .75120 & .000 & -8.5304 & -4.9241 \\
\hline & & Vertical growth pattern & $-11.52564^{*}$ & .72024 & .000 & -13.2545 & -9.7968 \\
\hline & \multirow[t]{2}{*}{ Average growth pattern } & Horizontal growth pattern & $6.72727^{*}$ & .75120 & .000 & 4.9241 & 8.5304 \\
\hline & & Vertical growth pattern & $-4.79837^{*}$ & .40429 & .000 & -5.7688 & -3.8279 \\
\hline & \multirow[t]{2}{*}{ Vertical growth pattern } & Horizontal growth pattern & $11.52564^{*}$ & .72024 & .000 & 9.7968 & 13.2545 \\
\hline & & Average growth pattern & $4.79837^{*}$ & .40429 & .000 & 3.8279 & 5.7688 \\
\hline \multirow[t]{6}{*}{ FMA } & \multirow[t]{2}{*}{ Horizontal growth pattern } & Average growth pattern & $-6.02727^{*}$ & 1.00241 & .000 & -8.4334 & -3.6212 \\
\hline & & Vertical growth pattern & $-10.28718^{*}$ & .96110 & .000 & -12.5941 & -7.9802 \\
\hline & \multirow[t]{2}{*}{ Average growth pattern } & Horizontal growth pattern & $6.02727^{*}$ & 1.00241 & .000 & 3.6212 & 8.4334 \\
\hline & & Vertical growth pattern & $-4.25991^{*}$ & .53949 & .000 & -5.5549 & -2.9650 \\
\hline & \multirow[t]{2}{*}{ Vertical growth pattern } & Horizontal growth pattern & $10.28718^{*}$ & .96110 & .000 & 7.9802 & 12.5941 \\
\hline & & Average growth pattern & $4.25991^{*}$ & .53949 & .000 & 2.9650 & 5.5549 \\
\hline \multirow[t]{6}{*}{ Sn-go gn } & \multirow[t]{2}{*}{ Horizontal growth pattern } & Average growth pattern & $-6.17727^{*}$ & 1.02924 & .000 & -8.6478 & -3.7068 \\
\hline & & Vertical growth pattern & $-10.90513^{*}$ & .98683 & .000 & -13.2738 & -8.5364 \\
\hline & \multirow[t]{2}{*}{ Average growth pattern } & Horizontal growth pattern & $6.17727^{*}$ & 1.02924 & .000 & 3.7068 & 8.6478 \\
\hline & & \begin{tabular}{|l|} 
Vertical growth pattern \\
\end{tabular} & $-4.72786^{*}$ & .55393 & .000 & -6.0575 & -3.3982 \\
\hline & \multirow[t]{2}{*}{ Vertical growth pattern } & Horizontal growth pattern & $10.90513^{*}$ & .98683 & .000 & 8.5364 & 13.2738 \\
\hline & & Average growth pattern & $4.72786^{*}$ & .55393 & .000 & 3.3982 & 6.0575 \\
\hline \multirow[t]{6}{*}{ LAFH } & \multirow[t]{2}{*}{ Horizontal growth pattern } & Average growth pattern & $-9.46364^{*}$ & 1.66108 & .000 & -13.4508 & -5.4765 \\
\hline & & Vertical growth pattern & $-13.38205^{*}$ & 1.59262 & .000 & -17.2049 & -9.5592 \\
\hline & \multirow[t]{2}{*}{ Average growth pattern } & Horizontal growth pattern & $9.46364^{*}$ & 1.66108 & .000 & 5.4765 & 13.4508 \\
\hline & & Vertical growth pattern & $-3.91841^{*}$ & .89398 & .000 & -6.0642 & -1.7726 \\
\hline & \multirow[t]{2}{*}{ Vertical growth pattern } & Horizontal growth pattern & $13.38205^{*}$ & 1.59262 & .000 & 9.5592 & 17.2049 \\
\hline & & Average growth pattern & $3.91841^{*}$ & .89398 & .000 & 1.7726 & 6.0642 \\
\hline \multirow[t]{6}{*}{3 molar angulations } & Horizontal growth pattern & Average growth pattern & -7.41818 & 5.34299 & .353 & -20.2431 & 5.4067 \\
\hline & & Vertical growth pattern & -5.48462 & 5.12281 & .536 & -17.7810 & 6.8118 \\
\hline & Average growth pattern & Horizontal growth pattern & 7.41818 & 5.34299 & .353 & -5.4067 & 20.2431 \\
\hline & & Vertical growth pattern & 1.93357 & 2.87554 & .780 & -4.9687 & 8.8358 \\
\hline & Vertical growth pattern & Horizontal growth pattern & 5.48462 & 5.12281 & .536 & -6.8118 & 17.7810 \\
\hline & & Average growth pattern & -1.93357 & 2.87554 & .780 & -8.8358 & 4.9687 \\
\hline lar Space & Horizontal growth pattern & Average growth pattern & 1.05909 & 1.59572 & .785 & -2.7712 & 4.8893 \\
\hline Disc & & Vertical growth pattern & 1.23333 & 1.52996 & .701 & -2.4391 & 4.9057 \\
\hline & Average growth pattern & Horizontal growth pattern & -1.05909 & 1.59572 & .785 & -4.8893 & 2.7712 \\
\hline & & Vertical growth pattern & .17424 & .85880 & .978 & -1.8872 & 2.2356 \\
\hline & Vertical growth pattern & Horizontal growth pattern & -1.23333 & 1.52996 & .701 & -4.9057 & 2.4391 \\
\hline & & Average growth pattern & -.17424 & .85880 & .978 & -2.2356 & 1.8872 \\
\hline & & & & & & & \\
\hline & & 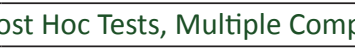 & 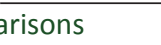 & & & & \\
\hline
\end{tabular}

collected from the archives of orthodontic clinics of three major academic institutions. The Orthopantomogram and Lateral cephalogram of all the patients who attended the clinic for orthodontic treatment in last three years were collected. All the cases of bilaterally impacted lower molars were collected as initial sample. The following inclusion and exclusion criteria were applied. As the patients having bilateral impacted mandibular third molars were less, all the lateral cephlaogram and OPG's were taken as sample after applying necessary inclusion and exclusion criteria.

\section{Inclusion criteria}

1. Bilaterally impacted lower third molars.

2. Patients with age $>18$ yrs

\section{Exclusion criteria}

1. Patients with craniofacial anomaly or syndromes

2. Presence of any other impacted teeth

3. Patients with history of previous Orthodontic treatment. All these criteria were checked in patient history records and OPG. After applying all these criteria, total 66 cases were selected. The lateral cephalogram of these 66 patients were used as study sample. All the lateral cephalograms were retraced and the measurements were revalidated by two orthodontists of the department. The various parameters which were considered for ascertaining the rotational pattern of the mandible were Bjork's analysis, Tweed analysis and Mc Namara's analysis. The angulations of third molars 
were measured as anterior angle formed at the junction of line drawn parallel to the long axis of the lower third molar passing through the furcation and line formed by joining gonion and menton (Fig 1). These angulations were recorded to correlate with various rotational pattern of mandible. The space available for third molar was calculated from the linear distance parallel to occlusal plane between distal surface of the second molar and J point (Fig 1). The J point was created at the intersection of occlusal plane with the anterior border of ramus of the mandible. The mesio distal width of the mandibular third molars was also measured. The adequacy of space available for third molar was calculated to rule out any other factors causing the impaction of third molars.

The data collected and distributed in three groups i.e. vertical, average and horizontal growers and the entire data was statistically evaluated.

\section{STATISTICAL ANALYSIS}

The consolidated data was stored and processed in an excel sheet and statistically evaluated using computer software package SPSS ver. 16 (SPSS Inc, Chicago, III). One way ANOVA test was applied with 95\% confidence interval and various sagittal parameters were analyzed for different skeletal types. The $\mathrm{P}$ value was set with a significance level of 0.05 .

Multiple comparison analysis was carried out using Post Hoc test. Various vertical parameters studied were compared among three skeletal classes. The differences in the growth pattern between all three skeletal groups were statistically significant. The differences of FMA and Sn-Go Gn between all three groups of growth patterns were found to be statistically highly significant (Table 2 and 3 ).

The differences of mean of third molar angulations in all three skeletal groups were found to be statistically insignificant (Table 2 and 3). The differences in the mean retro molar space discrepancy in all three skeletal classes of growth patterns were also found to be statistically not significant (Table 2 and 3).

Retro molar space and FMA was analyzed using ShapiroWilk test and it was concluded that the data do not follow the normal distribution, hence we cannot reject the alternative hypothesis ( $\mathrm{p}$-value are 0.032, and 0.000). Further values for Spearman's correlation coefficient indicates a weak negative monotonic relationship between FMA and retromolar space $(\mathrm{p}=.276)$

\section{RESULTS}

Among the total sample studied, 59.09\% patients were vertical growers, with mean FMA of $29.48 \pm 2.32$ and mean lower anterior facial height (LAFH) being $72.78 \pm 3.50 \mathrm{~mm}$. Among them, $74.35 \%$ were skeletal class II and none were Class III. Few patients, $7.57 \%$ were horizontal growers with mean FMA of $19.20 \pm 1.03$ and mean LAFH of $59.40 \pm 2.07$ $\mathrm{mm}$ (Table 1).

Among all vertical growers, $89.74 \%$ of cases had acute third molar angulations with mean value of $77.88^{\circ} \pm 10.33$. The mean third molar angulations in horizontal and average growers were also $72.4^{\circ} \pm 19.78$ and $79.81^{\circ} \pm 8.99($ Table 1$)$.

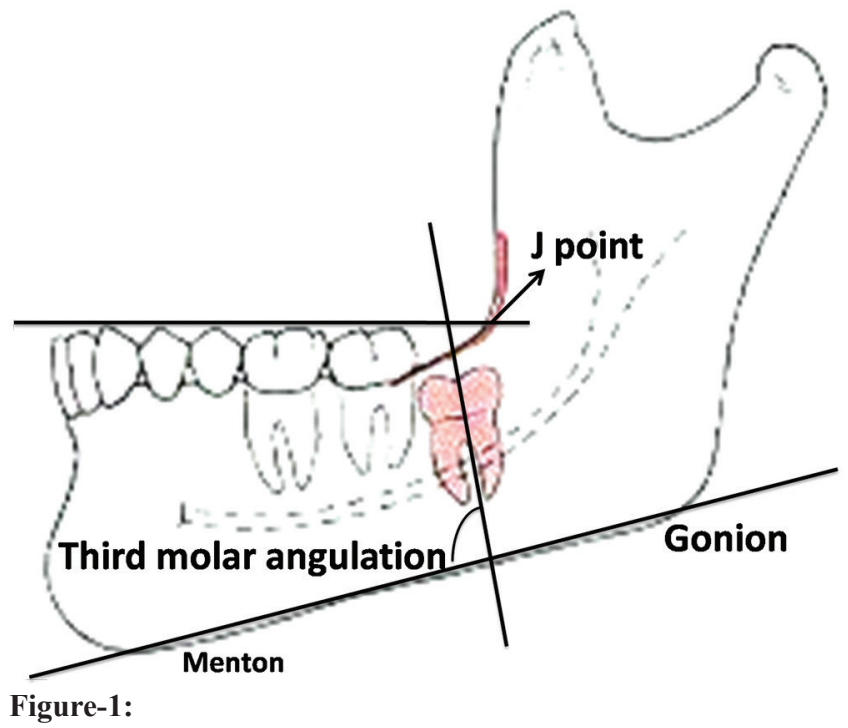

DISCUSSION

Prevalence of impaction of mandibular third molar nowadays are more common due lack of adequate space for eruption and smaller jaw size. ${ }^{14-16}$ It has been observed by few authors ${ }^{17}$ that mandibular third molar impaction is most commonly found in males with equal prevalence in both sides of the lower jaw. Mesioangular impactions were more prevalent as had been found in the present study also.

We in our previous unpublished manuscript attempted to correlate the sagittal dimension of the face with the impacted mandibular third molars and the space available for their favorable eruption of third molars. Present study intends to continue its preceding part in vertical dimensions of face. The present study attempts to analyze and correlate various vertical parameters of mandible and angulations of mandibular third molars. Further the retro molar space discrepancy has also been considered and comparisons being evaluated in all three groups of the study sample.

Although the number of horizontal growers in the selected study sample were very less in comparison to the previous studies, but the results are not in consensus with the conclusions drawn by few authors ${ }^{9}$, who suggested that the brachyfacial individuals have increased space for full eruption of the mandibular third molars over dolichofacial subjects. The present study however does indicate very weak correlation between mandibular plane angle and availability of retromolar space. Further, based on our statistical evaluation the primary cause of mandibular third molar impaction was found to be retromolar space discrepancy due to inadequate space between distal surface of second molar and anterior border of ramus or inappropriate angulations of mandibular third molar causing relative deficiency of retromolar space. Hence we suggest that along with the retromolar space availability, the mandibular third molar angulations also play a major deciding role for its eruption or impaction.

The present study also shows that the differences of mandibular third molar angulations in different skeletal patterns were found to be insignificant statistically which has also been advocated by various authors in previous studies. ${ }^{14-17}$ This proves that the various patterns of growth 
rotations occurring in the mandible may not be having any influence on the angulations of mandibular third molar and hence further affecting its eruption. Earlier studies by few authors had suggested methods for prediction of eruption of mandibular third molars, but no conclusive correlation was advocated pertaining to the affects of mandibular growth rotations on eruption pattern of third molars. ${ }^{18}$

Although the mesioangular impactions were significantly more prevalent in the entire study sample and especially in vertical growers, but this does not suggests that vertical growth pattern can be made attributable as other factors like availability of retromolar space also need to be ruled out before establishing cause for impaction of third molars.

\section{CONCLUSION}

Within the limitations of the present study it is concluded that the non eruption or impaction of mandibular third molar is independent of growth pattern of an individual and mandibular growth rotations doesn't have any significant effects on the retromolar space availability and mandibular third molar angulations. Further, excluding various syndromic and non syndromic anomalies and any significant medical conditions, the authors suggests that only the position and angulations of the mandibular third molar decides its eruption pattern. The impaction of mandibular third molar cannot be attributed to the differences in growth patterns in vertical dimensions of face.

\section{REFERENCES}

1. Bishara SE, Andreason G. Third molars: a review. Am J Orthod 1983; 83(1):131-137.

2. Andreasen, J.O., 1997. In: Andreasen, J.O., Peterson, J.K., Laskin, D.M. (Eds.), Textbook and Color Atlas of Tooth Impactions. Munksgaard, Copenhagen, pp. 222-223.

3. Bjork A, Jensen E, Palling M. Mandibular growth and third molar impaction. Acta Odont Scand 1956; 14 (3):231-271.

4. Shilling G. Development and eruption of the mandibular third molar and its response to orthodontic therapy. Angle Orthod 1973; 43 (5):271-278.

5. Broadbent $\mathrm{BH}$. The influence of the third molars on the alignment of teeth. Am J Orthod 1943; 29:312-330.

6. Begg PR. Stone Age man's dentition. Am J Orthod 1954; 40 (6): 298-312.

7. Gooris CGM, Artun J, Joondeph DR. Eruption of mandibular third molars after second molar extractions: a radiographic study. Am J Orthod Dentofacial Orthop 1990; 98 (4):161-167.

8. Kim T, A ${ }^{\circ}$ rtun J, Behbehani F, Artese F. Prevalence of third molar impaction in orthodontic patients treated non-extraction and with extraction of 4 premolars. Am J Orthod Dentofacial Orthop 2003; 123 (2):138-145.

9. Breik O., Grubor, D., 2008. The incidence of mandibular third molar impactions in different skeletal face types. Aust Dent J 53 (4), 320- 324

10. Kaplan RG. Some factors related to mandibular third molar impaction. Angle Orthod 1975; 45 (1): 153-158.

11. Richardson ME. The etiology and prediction of mandibular third molar impaction. Angle Orthod 1977;
47 (6): 165-172.

12. Burstone CJ, james RB, Legan H, Murphy GA, Norton LA. Cephalometrics for orthognathic surgery. J oral Surg 1978;36(4): 269-77.

13. Hassan AH. Mandibular cephalometric characteristics of a Saudi sample of patients having impacted third molars. Saudi Dent J. 2011; 23(2): 73-80.

14. Celikoglu M, Miloglu O, Kazanci F. Frequency of agenesis, impaction, angulation, and related pathologic changes of third molar teeth in orthodontic patients. J Oral Maxillofac Surg 2010;68 (5): 990-5.

15. Tsai HH. Factors associated with mandibular third molar eruption and impaction.J Clin Pediatr Dent.2005; 30 (2): 109-13.

16. Niedzielska IA, Drugacz J, Kus N, Kreska J. Panoramic radiographic predictors of mandibular third molar eruption. Oral Surg Oral Med Oral Pathol Oral Radiol Endod 2006; 102 (5): 154-8.

17. Muhamad AH, Nezar W. Prevalence of Impacted Mandibular Third Molars in Population of Arab Israeli: A Retrospective Study. IOSR-JDMS. 2016; 15 (1): 809.

18. Behbehani F, Årtun J, Thalib L. Prediction of mandibular third-molar impaction in adolescent orthodontic patients. Am J Orthod Dentofacial Orthop 2006; 130 (4):47-55.

Source of Support: Nil; Conflict of Interest: None

Submitted: 22-11-2018; Accepted: 01-11-2018; Published online: 02-01-2019 